\title{
Optimization of Process Parameters of Copper Composites Produced via Friction Stir Processing
}

\author{
B N V S Ganesh Gupta $\mathrm{K}^{+*}$ and D Santha Rao ${ }^{\dagger}$ \\ †Mechanical Engineering Department, BVC Engineering College, Odalarevu, India \\ Received 10 Jan 2018, Accepted 15 March 2018, Available online 21 March 2018, Vol.6, No.1 (March 2018)
}

\begin{abstract}
Increasing demands for operating properties of fabricated elements on one hand, and a necessity of reducing mass of a structure on the other, triggers materials engineering research into producing surface layers representing required functional properties. Methods commonly used in the production of surface layers, such as surfacing, spraying or remelting with a laser beam have been known for years. A new method is the friction stir processing (FSP) of surface layers. The FSP process is primarily used for the modification of microstructure in near-surface layers of processed metallic components this deformation is produced by forcibly inserting a non-consumable tool into the workpiece, and revolving the tool in a stirring motion as it is pushed laterally through the workpiece. This is promising process for the automotive and aerospace industries where new material will need to be developed to improve resistance to wear, creep, and fatigue. The main objective of this project is to be producing copper reinforced metal matrix composite layers using micro sized TiB2 particles via friction stir processing (FSP) in order to enhance surface mechanical properties. Taguchi method was used to optimize these factors for maximizing the mechanical properties of surface composites. The fabricated surface composites were examined by optical microscope (OM) and scanning electron microscopy (SEM) for dispersion reinforcement particles. It was found that TiB2 particles are uniformly dispersed in the stir zone. Mechanical properties like tensile, Impact, hardness, were also evaluated. The results showed that functional characteristics of surface composites increased with the increase in vol. \% of the micro sized TiB2 reinforcement particles. The observed mechanical properties are correlated with microstructure and fracture features.
\end{abstract}

Keywords: Friction Stir Processing, Copper, TiB, Micro reinforcement particles, Micro Structure, Stir Zone, Orthogonal Array, Signal -to-Noise ratio, Grey Relational Analysis, ANOVA.

\section{Introduction}

Friction stir processing (FSP), a solid state technique based on the principle of Friction stir welding (FSW) is used for material processing in order to modify the microstructure and mechanical properties of surface composites and fabricate the surface composites. Over the last several decades they has been considering interest in the use of copper based metal matrix composites (CMMCs). For many applications pure $\mathrm{Cu}$ cannot be used because of its low strength therefore improvement in the properties of copper has become essential for its applications in cutting edge technological applications. The improvement of the mechanical properties of copper is important for its use in larger number of fields. Composite materials offer several applications in the aerospace, electronics, automotive, and ship building industries as they have certain advantages over other conventional metals.

*Corresponding author: B N V S Ganesh Gupta K DOI: https://doi.org/10.14741/ijaie/v.6.1.1
The major benefit of copper based composites is their low density, improved fatigue, superior corrosion resistance and higher specific strength in many engineering applications, the surface properties decides life of the component rather than their bulk properties. The surface layer reinforced with ceramic particles (TiB2) is normally called surface composites. Through several techniques are available to fabricate surface composites, friction stir processing(FSP) is simple, green and low energy consumption route based on the principle of FSW to fabricate the surface composites with superior results.

Titanium Di-boride (TiB2) particles are of great technological importance because of their applications as reinforcement for metal matrix composites. High mechanical strength, as well as high stiffness and hardness, are the main TiB2 characteristics. Furthermore, in contrast to most ceramic materials, TiB2 is electrically and thermally conductive. Metal transfer, generated between the tool shoulder and the work piece plate, place an important role in influencing the mechanical properties during FSP. 


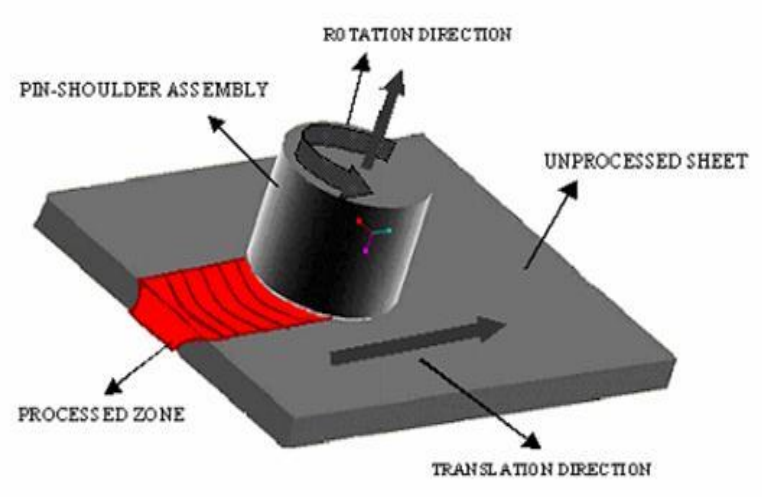

Fig 1 Friction Stir Processing

An FSP tool consists of a shoulder and a pin. Firstly the tool without pin is used and moves traverse along the groove consisting of reinforcement particles thus forging it latter the tool with pin is used moves along the desire line to cover the region underneath the shoulder. Friction between the tool and work piece results in localized heating that softens and plasticizes the work piece during this process, the material undergoes plastic deformation, thus resulting in grain refinement to improve its mechanical properties.

Table1. Mechanical Properties of base metal

\begin{tabular}{|c|c|c|c|c|c|}
\hline Material & UTS/Mpa & YS/Mpa & $\%$ EL & Micro hardness/HV & IT/J \\
\hline Pure Copper & 255 & 210 & 10 & 80 & 12 \\
\hline
\end{tabular}

Table 2 Chemical Properties of base metal

\begin{tabular}{|c|c|c|c|c|c|}
\hline Component & $\mathrm{Cu}$ & $\mathrm{Zn}$ & $\mathrm{Pb}$ & $\mathrm{Fe}$ & $\mathrm{Bi}$ \\
\hline Weight \% & 99.99 & $<0.026$ & $<0.05$ & $<0.0025$ & $<<0.001$ \\
\hline
\end{tabular}

\section{Experimental design using Taguchi's method}

Taguchi's technique has been used widely in engineering design. It is an efficient tool which enables the up gradation of the performance of the product, process and design with significant prediction of cost and time. The main trust of Taguchi's technique is the use of parameter design, which is an engineering method for product or process design that focuses on determining the parameter settings producing the best Level of a quality characteristic with minimum variation. It is simple, efficient and systematic approach to determine optimal process parameters. Taguchi design provides a powerful and efficient method for designing processes that operate consistently and optimally over a variety of conditions. In friction stir processing the parameters used in this experimental work are tool travel speed, tool rotation speed, and vol. \% age of reinforcement particles. Feasible levels of the process parameters were chosen in such a way that the surface composite should be free from defects.

\subsection{Experimental Layout $L_{9}$ Orthogonal Array}

Table 3 Experimental Layout

\begin{tabular}{|c|c|c|c|}
\hline \multirow{2}{*}{ Expt. No } & \multicolumn{3}{|c|}{ Process Parameters } \\
\cline { 2 - 4 } & Tool travel Speed (mm/min) & Tool rotational speed/rpm & TiB $_{2}$. Vol\% \\
\hline FSP 1 & 20 & 900 & 8 \\
\hline FSP 2 & 20 & 1120 & 16 \\
\hline FSP 3 & 20 & 1400 & 24 \\
\hline FSP 4 & 30 & 900 & 16 \\
\hline FSP 5 & 30 & 1120 & 24 \\
\hline FSP 6 & 30 & 1400 & 8 \\
\hline FSP 7 & 40 & 900 & 24 \\
\hline FSP 8 & 40 & 1120 & 8 \\
\hline FSP 9 & 40 & 1400 & 16 \\
\hline
\end{tabular}

In this study, the analysis was carried out using statistical software MINITAB-17.Hence orthogonal array was selected in the present work. Each condition of experiments was repeated twice in order to reduce the noise error effects. The quality characteristics in the analysis of $\mathrm{S} / \mathrm{N}$ ratio. The $\mathrm{S} / \mathrm{N}$ ratio for each combination of the process parameters is computed based on the Signal Noise analysis, such as ultimate tensile strength (UTS), yield strength (YS), percentage of elongation (\% EL),micro hardness (HV)and impact toughness (IT) of surface composite were evaluated for all the trials and then statistical analysis of variance was carried out. Based on analysis of variance, the contribution of each element influencing the quality characteristic is evaluated. The optimum combinations of process parameters were predicted and verified.

\subsection{Experimental Procedure}

- Commercially available pure copper (C11000) plates of $200 \mathrm{~mm}$ length, $100 \mathrm{~mm}$ width, and $6 \mathrm{~mm}$ thickness, micro sized Titanium Di-boride $\left(\mathrm{TiB}_{2}\right)$ was used as reinforcement particle.

- The average size of the reinforcement particle is $120 \mathrm{~nm}, 80 \mathrm{~nm}$ respectively and SEM microstructure of as received, in this project work to fabricate the surface composites with a vertical milling machine (Make: HMT FN-3, 10hp, 1800 Rpm).

- The copper plates of required dimensions cut from the given plate using Power hacksaw machine. After that, the sharp corners of the samples are rounded by filing and these surface plates were cleaned with grinding paper and methanol before processing.

- A groove was made in the middle of the copper plate using slitting cutter on milling machine and the groove size was varied as groove width $0.5 \mathrm{~mm}$, $1 \mathrm{~mm}, 1.5 \mathrm{~mm}$, groove depth $4.5 \mathrm{~mm}$ and groove length $200 \mathrm{~mm}$.The TiB2 reinforcement particles was filled in the groove.

- The tool material used as H13 Tool Steel. It consisted of a shoulder with a diameter of $22 \mathrm{~mm}$ and pin with diameter $4.5 \mathrm{~mm}$ and length $6 \mathrm{~mm}$ respectively. 
- This tool is fitted into the tool holder and work piece is rigidly clamped to machine table using fixtures. The $\mathrm{TiB}_{2}$ reinforcement particles were compressed into the groove and the upper surface of the groove was closed with a FSP tool without pin to prevent the $\mathrm{TiB}_{2}$ particles to escape from the groove. In the next stage the tool is plunged with the pin into the plate to stir the material.

- $\quad$ The tool rotation speed and tool travel speed was adjusted at 900, 1120 and $1400 \mathrm{rpm}$, and 20, 30, $40 \mathrm{~mm} / \mathrm{min}$ along the axis of the work piece with different Vol. \% age of reinforced particles as 8, 16 and 24 to produce the surface composites.

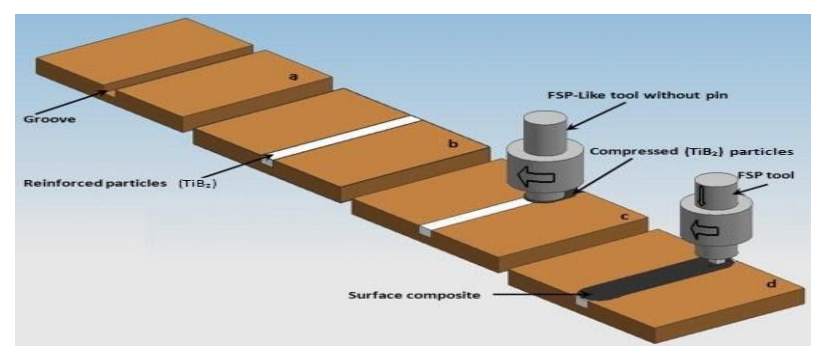

Fig.2 Friction Stir Process

After FSP, microstructure observations were carried out at the cross section of stir zone (SZ) of surface composites normal to the FSP direction mechanically polished and etched with $10 \%$ potassium dichromate in 100cc of water+2cc of Conc. HCL. Microstructure changes were observed by optical microscope (OM) in the SZ/N. The tensile specimens were prepared as per the ASTM E8 Standards by wire cut EDM to the required dimensions which is transverse to the $S Z$. The tensile test was conducted with the help of a computer control universal testing machine. The impact specimens were prepared as per ASTM A370 Standards. Charpy V notch impact test was carried out using pendulum type impact testing machine at room temperature. Micro hardness test was carried out using Vickers digital micro hardness tester with a $0.5 \mathrm{~kg}$ load for $10 \mathrm{sec}$ duration at the cross section of SZ of surface composites normal to the FSP direction as per ASTM E92 Standard.

\section{Results and Discussions}

\subsection{Microstructure}

The material is under severe plastic deformation (SPD) that causes a fine grain structure with high angle boundaries. The taper cylindrical threaded tool pin profile made uniform distribution of TiB2 reinforcement particles in $\mathrm{cu}$ based metal matrix composites. FSP can be successfully used for fabrication of micro composite layer with uniform distribution of TiB2 particles at low heat input under condition of $2^{\circ}$ tilt angle and combination of various process parameters such as (Tool rotational speed, Tool travel speed, \%.of vol. fraction).The heat input that causes annealing and grain growth in sides region of SZ. Agglomeration of TiB2 particles cannot be observed.

The main difference between HAZ and BM is grain boundary. Grain boundary in HAZ is not obvious as in $\mathrm{BM}$, but because of annealing, grains growth in HAZ favored. No cluster of particles is seen. Further, there is no segregation of particles along the grain boundaries. The distribution is almost intergranular. The mechanical tribological properties of CMMCs are dictated by the nature of distribution. Homogeneous and intergranular distribution is preferred to obtain superior properties.

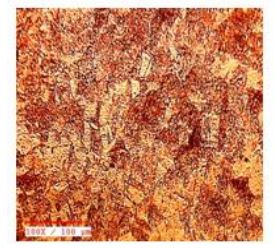

(a) BM

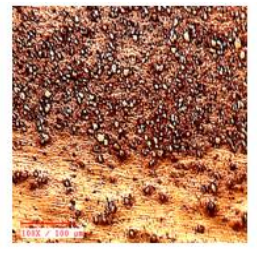

(b) FSP 4

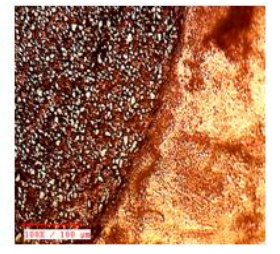

(c) FSP 7
Fig.3 Optical microstructures of Base metal and FSP 4, FSP 7 Surface composites

SEM micrographs of CMCs reinforced with $\mathrm{TiB}_{2}$ ceramic particles at higher magnification. The etchant used in this work reveals the grain boundaries. The interface between the copper matrix and ceramic particles is clear without the presence of pores on reaction products. $\mathrm{TiB}_{2}$ ceramic particles bonded well with the copper matrix. No such pores are observed near any ceramic particle. This can be related to sufficient material flow and plasticization of copper under chosen experimental condition. Good interfacial bonding is prerequisite in spite of homogeneous distribution to enhance the properties.

\subsection{Mechanical properties}
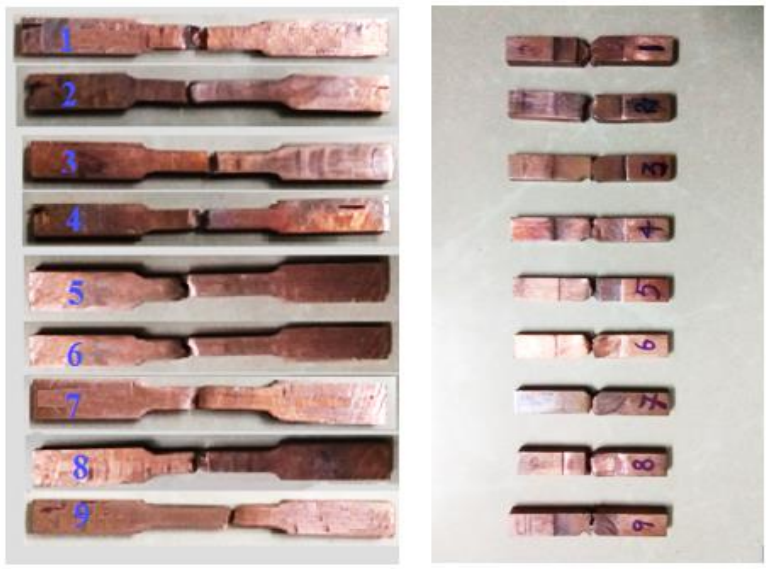

Fig.4 Micro Friction Stir Processed TENSILE \& IMPACT\& Tested Specimens (FSP1-FSP9)

The mechanical properties of CMCs are generally influenced by the type, size, and shape, \% of vol. fraction and spatial distribution of ceramic particles. 
Increased in the UTS, YS of the surface composites over the pure copper matrix is due to the grain refinement of copper in the surface composite which can be related to the interaction between the powder particles and dislocations with the matrix. It is also found that with increase in the addition of TiB2 reinforcement particles and is uniformly distributed on copper matrix and thus improving strength at elevated temperature.

The elongation of the FSPed specimens with addition of TiB2 particles were reduced as compared to the pure copper due to the increase in \%.vol. of reinforcement particles which increases the effective slip distance of dislocations during the deformation. The impact toughness of the surface composites values were observed at various process parameters and higher impact toughness values were observed at higher vol. Fraction of the reinforced particles with copper matrix. These characteristics to the addition of reinforced particles which causes softening of the matrix due to frictional heat of the tool and shoulder pin.

\subsection{Micro hardness}

The micro hardness profile shows that hardness value in the SZ is much higher than that of the BM. The micro hardness of as received copper was $80 \mathrm{Hv}$. The reinforcement of ceramic particles increase the micro hardness above $110 \mathrm{Hv}$. $\mathrm{Cu}-\mathrm{TiB}_{2} \mathrm{CMCs}$ recorded a max hardness of $119.5 \mathrm{Hv}$. The rise in micro hardness of CMCs indicates that the ceramic particles contributed remarkably to the strengthening of the copper matrix. The hindrance to dislocation movement by higher dislocation density enhances hardness. Higher hardness/strengthening can be attributed in the stir zone due to following factors;

- Distribution of $\mathrm{TiB}_{2}$ particles in the pure $\mathrm{Cu}$ matrix as a hard phase.

- The hardness of the ceramic particles is extremely higher to that of copper matrix.

- The grain size of CMCs is smaller to that of the copper matrix due to grain refinement of ceramic particle. The fine grains improve the hardness.

\section{Determination of optimal machining parameters}

Grey Relational Analysis (GRA): Taguchi's method is focused on the effective application of engineering strategies rather than advanced statistical techniques. The primary goals of Taguchi method are:

- A reduction in the variation of a product design to improve quality and lower the loss imparted to society. - A proper product or process implementation strategy, which can further reduce the level of variation.

The steps involved in Taguchi's Grey Relational Analysis are:
STEP 1-: The transformation of S-N Ratio values from the original response values was the initial step. For that the equations of "larger the better", "smaller the better" and "nominal the best' were used. Subsequent analysis was carried out on the basis of these $\mathrm{S} / \mathrm{N}$ ratio values. This is shown in table 5.

$$
\begin{aligned}
& \text { Type1: } \mathrm{S} / \mathrm{N}_{\mathrm{HB}}=-10 \log _{10}\left[\left(\frac{1}{n}\right)\left(\sum \frac{1}{Y_{i j}^{2}}\right)\right] \\
& \text { Type1: } \mathrm{S} / \mathrm{N}_{\mathrm{LB}}=-10 \log _{10}\left[\sum \frac{Y_{i j}^{2}}{n}\right] \\
& \text { Type1: } \mathrm{S} / \mathrm{N}_{\mathrm{NB}}=-10 \log _{10}\left[\frac{1}{S^{2}}\right]
\end{aligned}
$$

Where

$Y_{i j}$ is the value of the response

' $j$ in the $i^{\text {th }}$ experiment condition, with $i=1,2,3 \ldots n ; j=$ $1,2 \ldots \mathrm{k}$ and $\mathrm{S}^{2}$ are the sample mean and variance.

STEP 2: In the $2^{\text {nd }}$ step of the grey relational analysis, pre-processing of the data was first performed for normalizing the raw data for analysis. This is shown in Table 6. The following formula to avoid the effect of adopting different units and to reduce the variability. The normalized output parameter corresponding to the larger-the-better criterion can be expressed as,

$x_{i}^{*}=\frac{x_{i}^{0}(k)-\min x_{i}^{0}(k)}{\max x_{i}^{0}(k)-\min x_{i}^{0}(k)}$

STEP 3: The grey relational coefficient, is calculated to express the relationship between the larger (best) and actual normalized experimental results. Before that the deviation sequence for the reference and comparability sequence were found out. These are given in Table 6 and the grey relational coefficient can be expressed as,

$$
\begin{aligned}
& \xi_{i}(k)=\frac{\Delta_{\min }+\zeta \Delta_{\max }}{\Delta_{0 i(k)}+\zeta \Delta_{\max }} \\
& \Delta_{\mathbf{0} i=} \quad \boldsymbol{x}_{\mathbf{0}}(\boldsymbol{k})=\boldsymbol{x}_{\boldsymbol{i}}(\boldsymbol{k})
\end{aligned}
$$

$X_{i}(\mathrm{k})$ denotes the comparability sequence. ' $\xi$ ' is distinguishing or identified coefficient. The Value of $\xi$ is the smaller and the distinguished ability is the larger. $\xi=1$ is generally used.

Step 4: The grey relational grade was determined by averaging the grey relational coefficient corresponding to each performance characteristic. The overall performance characteristic of the multiple response process depends on the calculated grey relational grade. The grey relational grade can be expressed as,

$$
\gamma_{i=\frac{1}{n}} \quad \sum_{k=1}^{n} \xi(k)
$$

Where, $\Upsilon_{i}$ is the grey relational grade for the $\mathrm{J}^{\text {th }}$ experiment and $\mathrm{k}$ is the number of performance characteristics. 
Step 5: Determination of the Optimal Factor and its Level Combination. Since the experimental design is orthogonal, it is possible to separate out the effect of each machining parameter on the grey relational grade at different levels.

The larger the grey relational grade, the better is the multiple performance characteristics. However, the relative importance among the machining parameters for the multiple performance characteristics still needs to be known, so that the optimal combinations of the machining parameter levels can be determined more accurately.

\section{Taguchi Analysis for Grey Relational Grade}

Table 4 For Grey Relational Grade (Larger is Better)

\begin{tabular}{|l|l|l|l|}
\hline \multirow{2}{*}{ Level } & \multicolumn{3}{|c|}{ Grey Relational Grade } \\
\cline { 2 - 4 } & TS & RS & Vol.\% \\
\hline $\mathbf{1}$ & 0.5420 & 0.5512 & 0.5199 \\
\hline $\mathbf{2}$ & 0.5598 & 0.5236 & 0.5211 \\
\hline $\mathbf{3}$ & $\mathbf{0 . 5 8 9 6}$ & $\mathbf{0 . 6 1 6 7}$ & $\mathbf{0 . 6 5 0 3}$ \\
\hline Delta & 0.0476 & 0.0931 & 0.1304 \\
\hline Rank & $\mathbf{3}$ & $\mathbf{2}$ & $\mathbf{1}$ \\
\hline
\end{tabular}

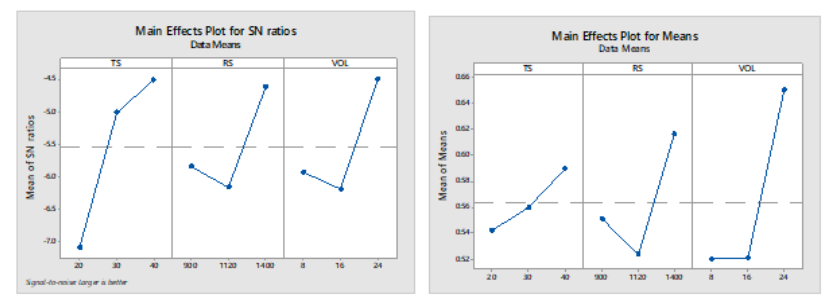

Tool travel speed (mm/min) 40, Tool Rotational speed/rpm 1400, Vol. \%age 24 is the optimal parameter level for the higher grey relational Grade The prediction of Optimum value for Grey Relational Grade:

Predicted Response $=$ Average of $\mathrm{A} 3+$ Average of $\mathrm{B} 3+$ Average of C3 - 2 x Mean of response ( $\left.\mathrm{Y}_{\mathrm{ij}}\right)$.

\subsection{Conformation test at Optimal Parameter Level obtained from Grey Relational Analysis:}

The confirmation experiment was conducted at the Optimal Process Parameters namely Tool travel speed at level 3 (40 $\mathrm{mm} / \mathrm{min})$, Tool rotational speed at level 3 (1400 rpm), and Vol. \% reinforced particles at level 3 (24\%) to evaluate Response quality characteristics were represented.

Table: 6 Conformation Test Results at Optimal level of Parameters

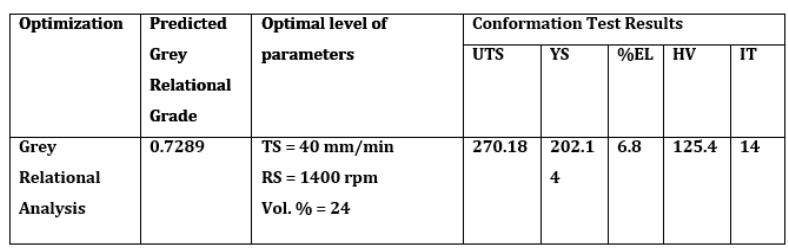

The comparison again shows the good agreement between the Optimal predicted (A3B3C3) and the experimental (A3B1C3) Values

Table 5 Confirmation Results

\begin{tabular}{|c|c|c|}
\hline \multirow{2}{*}{ Level } & \multicolumn{2}{|c|}{ Optimal Process Parameters } \\
\cline { 2 - 3 } & Predicted & Experiment \\
\cline { 2 - 3 } & A3B3C3 & A3B1C3 \\
\hline UTS & 269.46 & 269.77 \\
\hline YS & 189.2 & 184.51 \\
\hline \%EL & 6.08 & 5.48 \\
\hline HV & 122.3 & 119.5 \\
\hline IT & 16 & 14 \\
\hline
\end{tabular}

\section{Analysis of Variance \& Percentage of contribution}

The main purpose of the ANOVA is the application of a statistical method to identify the effect of individual factors on the process responses. The Taguchi experiment method could not judge the effect of individual parameters on the entire process. The percentage of contribution using ANOVA is used to compensate for this effect. The percentage of contribution is the portion of the total variation observed in the experiment attributed to each significant factors and interaction which is reflected. In order to find the effect of process parameters on various responses. The calculated F-values of the ANOVA for various responses determine the relative significance of different process parameters. Results of ANOVA revealed that the process parameters have significant effect on all the quality Characteristics.

Based on the results, Vol. \%age of reinforcement particles (TiB2) is found to be the most influencing process parameter followed by tool tilt angle and concave angle at the tool shoulder. The percentage of contribution is the portion of the total variation observed in the experiment attributed to each significant factor. The percentage of contribution is the function of the sum of the squares for each significant item and it indicates the relative power of a factor to reduce the variation. If the factor levels are controlled precisely then the total variation could be reduced by an amount which is indicated by percentage of contribution. The percentage of the vol. \%age of reinforcement Particles are higher because these particles play an important role in material strength through dislocation and grain boundary pinning mechanism. The presence of hard reinforcement particles thus enhances the hardness.

\section{Analysis of Variance \& Percentage of contribution}

The main purpose of the ANOVA is the application of a statistical method to identify the effect of individual factors on the process responses 
Table: 7 Anova for Grey Relational Grade

\begin{tabular}{|l|l|l|l|l|l|}
\hline $\begin{array}{l}\text { Process } \\
\text { Paramete } \\
\text { rs }\end{array}$ & $\begin{array}{l}\text { Degree of } \\
\text { Freedom } \\
\text { (DF) }\end{array}$ & $\begin{array}{l}\text { Sum of Squares } \\
\text { (SS) }\end{array}$ & $\begin{array}{l}\text { Adj-mean Sum } \\
\text { of Squares } \\
\text { (MS) }\end{array}$ & F-ratio & $\begin{array}{l}\text { \%.of } \\
\text { Contribution }\end{array}$ \\
\hline TS & 2 & 0.027378 & 0.013689 & 4.99 & 49.77 \\
\hline RS & 2 & 0.004011 & 0.0020055 & 0.73 & 7.29 \\
\hline Vol. \% & 2 & 0.018134 & 0.009067 & 3.30 & 32.97 \\
\hline Error & 2 & 0.005485 & 0.0027425 & & 9.97 \\
\hline Total & 8 & 0.055009 & & & 100 \\
\hline
\end{tabular}

\section{Results \& Discussions}

After performing the experiment for all 9 runs of $\mathrm{Cu}$ $\mathrm{TiB}_{2}$ Surface composites and measuring the output parameters like Ultimate tensile strength, Yield Strength, \%of Elongation, Micro Hardness and Impact Strength of Copper metal matrix composite material.

Main Effect Plots for Friction Stir Processed Input Parameters V/S Output Parameters

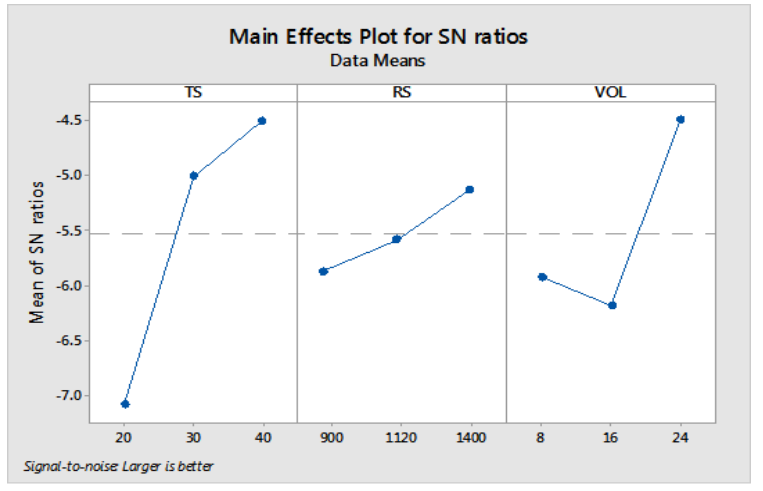

Fig.5 Grey Relational Grade

Tool travel speed (mm/min) 40, Tool Rotational speed/rpm 1400, Vol. \%age 24 is the optimal parameter level for the higher grey relational Grade.

\subsection{Confirmation test at Optimal Parameter Level obtained from Grey Relational Analysis}

The confirmation experiment was conducted at the Optimal Process Parameters namely Tool travel speed at level 3 (40 $\mathrm{mm} / \mathrm{min})$, Tool rotational speed at level 3 (1400 rpm), and Vol. \% reinforced particles at level 3 (24\%) to evaluate Response quality characteristics.

Table: 8 Confirmation Test Results at Optimal level of Parameters

\begin{tabular}{|c|c|c|c|c|c|c|c|}
\hline \multirow[b]{2}{*}{$\begin{array}{c}\text { Optimizati } \\
\text { on }\end{array}$} & \multirow{2}{*}{$\begin{array}{c}\text { Predicted } \\
\text { Grey } \\
\text { Relational } \\
\text { Grade }\end{array}$} & \multirow[b]{2}{*}{$\begin{array}{c}\text { Optimal level of } \\
\text { parameters }\end{array}$} & \multicolumn{5}{|c|}{ Conformation Test Results } \\
\hline & & & $\begin{array}{l}\text { UTS } \\
\text { (Mpa) }\end{array}$ & $\begin{array}{c}\text { YS } \\
\text { (Mpa) }\end{array}$ & \%EL & $\begin{array}{c}\mathrm{H} \\
\text { (Hv) }\end{array}$ & $\begin{array}{l}\text { IT } \\
\text { (d) }\end{array}$ \\
\hline $\begin{array}{c}\text { Grey } \\
\text { Relational } \\
\text { Analysis }\end{array}$ & 0.7215 & $\begin{array}{c}\text { TS }=40 \mathrm{~mm} / \mathrm{min} \\
\text { RS }=1400 \mathrm{rpm} \\
\text { Vol. } \%=24\end{array}$ & 270.18 & $\begin{array}{c}202.1 \\
4\end{array}$ & 6.8 & $\begin{array}{c}125 . \\
4\end{array}$ & 14 \\
\hline
\end{tabular}

The following table shows the corresponding improvements in Ultimate Tensile Strength (UTS), Hardness (Hv), and Impact Strength (IT) is 5.95\%, $49.2 \%, 16.6 \%$ respectively. It is clearly shown that by applying Multi variable Optimization for process parameters optimization in FSP, greatly improved the output Response Variables.

\subsection{ANOVA Analysis}

From ANOVA for based Friction Stir Processed Grey Relational Grade:

The ANOVA analysis is conducted to know the percentage contribution of the input parameters on output parameters. The percentage of contribution is the portion of the total variation observed in the experiment attributed to each significant factors and interaction which is reflected. Tool Travel speed is $49.77 \%$, Tool rotation speed is $7.29 \%$ and Vol. \% of Reinforced particles is $32.97 \%$.

This shows that the Tool Travel speed and Vol. \% of Reinforced particles are the most influence parameters in increases of Response characteristics.

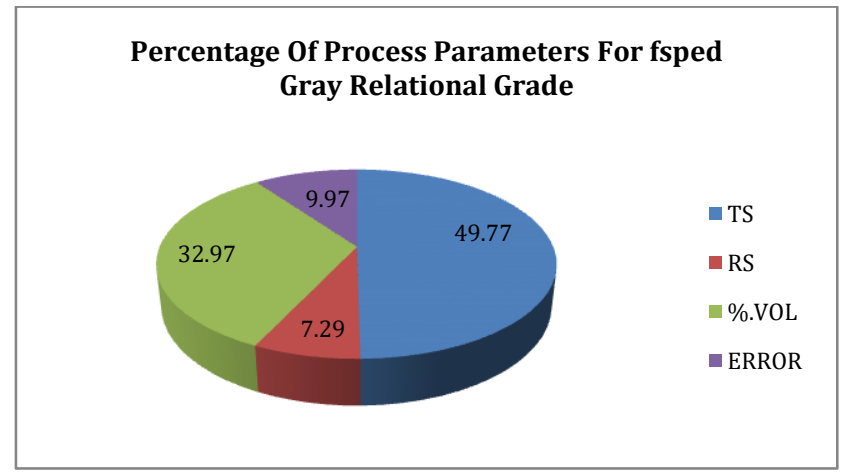

Fig.6 \% of process parameters for Friction Stir Processed grey relational grade

\section{Conclusion}

The experiments were conducted to optimize the influence of process parameters such as Tool travel speed ( $\mathrm{mm} / \mathrm{min})$, Tool rotational speed (rpm), and Vol. $\%$ ( $\mathrm{TiB}_{2}$ Particles) on microstructure and mechanical properties of $\mathrm{Cu}-\mathrm{TiB}_{2}$ surface composites fabricated via Friction stir processing. The following conclusions were drawn from the present study.

- Designing of grooves was very effective to achieve agglomeration free surface composite where the Micro $\mathrm{TiB}_{2}$ (Titanium Di-boride) reinforcement particles were well bonded with copper matrix. The micro FSPed on the stir zone exhibited better mechanical properties than the as received pure copper

- Good interfacial bonding was observed in between Copper and Titanium Diboride $\left(\mathrm{TiB}_{2}\right)$ reinforcement particles by micro structural analysis. Stir zone has fine and equiaxed grains and distribution of $\mathrm{TiB}_{2}$, particles 
in the matrix is uniform. No intermetallic compound was formed after FSP and observed no defects after processing.

- Micro Composites tangibly showed better mechanical properties compared with non-reinforced Sample, and the improvements in ultimate tensile strength (273.02/Mpa) by (7.06\%), hardness $(119.5 \mathrm{Hv})$ by $(42.26 \%)$, and impact strength $(14 / \mathrm{J})$ by $(16.67 \%)$ were attained in the 24 Vol. \% $\mathrm{TiB}_{2}$ FSPed Copper Composites.

- Confirmation test at Optimal Parameter levels obtained from grey relational analysis (Micro Composites), significantly improvements in ultimate tensile strength $(275.82 / \mathrm{Mpa})$ by $(8.16 \%)$, hardness $(125.4 / \mathrm{Hv})$ by $(49.2 \%)$, and impact strength $(14 / \mathrm{J})$ by $(16.67 \%)$ were attained in the $24 \mathrm{Vol}$. \% $\mathrm{TiB}_{2}$ sped Copper Composites.

- Mechanical properties of $\mathrm{Cu}-\mathrm{TiB}_{2}$ Surface composites increased with increase in the vol.\% age of reinforcement particles, whereas the specimens of micro FSPed with $\mathrm{TiB}_{2}$ particles exhibits a poor elongation and Yield strength. The hardness $(125.4 / \mathrm{Hv})$ of the speed stir zone increased by $49.2 \%$ higher than that of the pure copper $(84 / \mathrm{Hv})$. Use of MICRO Ti $\mathrm{T}_{\mathrm{B} 2}$ (Titanium Di-boride) reinforcement particles in Friction Stir Processing as composite material increases hardness at greater extent.

\section{From Grey Relational analysis}

Grey Relational analysis was applied in this work to improve the multi-response characteristics such as Ultimate Tensile strength (UTS), Yield Strength (YS), Percentage of Elongation (\%EL), Hardness $(\mathrm{H})$, and Impact Strength (IT).The conclusions of this work are summarized as follows:

The optimal parameters combination was determined as $A_{3} B_{3} C_{3}$ i.e. Tool travel speed at level $3(40 \mathrm{~mm} / \mathrm{min})$, Tool rotational speed at level 3 (1400 rpm), and Vol. \% reinforced particles at level 3 (24\%) were checked with experimental results and a good agreement was found, by applying Multi variable Optimization for process parameters optimization in FSP, greatly improved the output Response Variables

This work demonstrates the method of using Taguchi Grey Analysis methods for optimizing the FSP parameters for multiple response characteristics From ANOVA for Based Friction Stir Processed Grey Relational Grade:

Tool Travel speed and Vol. \% of Reinforcement particles are the most influence parameters in increases of Response characteristics

\section{References}

Raju L. Suvarna, A. Kumar (2014) Influence of $\mathrm{Al}_{2} \mathrm{O}_{3}$ Particles on the microstructure and mechanical properties of copper surface composites fabricated by friction stir processing.Mater Defence Technology 10 375-383.

H.R. Akramifed, M. Shmanian, M. Sabbaghian, M. Esmailzadeh (2014), Microstructure and mechanical properties of $\mathrm{Cu} / \mathrm{SiC}$ metal matrix composite fabricated via friction stir processing , Materials and Design 54, 838-844.

Isaac Dinaharan, Ramasamy Sathiskumar, Nadarajan Murugan (2016), Effect of ceramic particulate type on microstructure and mechanical properties of copper matrix composites synthesized by friction stir processing jmr\&t JMRTEC-201; RESTECHNOL.

V.Jeganathan Arulomoni, Ranganath M.S. R.S. Mishra , Friction stir processed Copper Matter ISSN: 2347-6176

Cartigueyen Srinivasan and Mahadevan Karunanithi (2015), Fabrication of surface level $\mathrm{Cu} / \mathrm{SiCp}$ Nano compoites by friction stir processing Route, Hindawi, Article ID 612617

Devaraju A Kumar A, Kotiveerachari B. (2013) Influence of Rotational speed and reinforcement on mechanical properties of Al hybrid composites via FSP Mater Des;45;576-85.

V. Kishan, Aruri Devaraju, K. Prasanna Lakshmi (2016), Influence of Volume percentage of Nano TiB2 Particles on tribological \& mechanical behaviour of 6061-T6 Al alloy nano- surface composite layer prepared via friction stir process.Mater Sci ENG Defence Technology.

Md.Norul Hooda, Dr. Ranganath M.Singari, V. Jaganathan Arumoni, Friction Stir Processing (FSP) of Copper and enhancement of Its Mechanical properties Using Graphite Powder (C).

Sathiskumar R Murugan N, Dinaharan I, Vijay SJ. (2013)Characterization of boron carbide Particulate reinforced in Situ Copper surface composites Synthesized using friction stir processing. Mater Charact; 84:16-27.

Bahram A.Khiyavai, Abdolhessein Jalali Aghchai, Mohammdreza Arababtafti, Mohammad Kazem Besharati Givi, Jalal Jafari (2014), Effect of friction stir processing on mechanical properties of surface composite of $\mathrm{Cu}$ reinforced with Cr Particles, Advanced Material Research Vol.829, pp 829,851

Zahid A. Khan ,Arshad N.SIddiquee, Noor Zaman Khan, Urfi Khan, G.A.Quadir (2014) Multi response optimization of WEDM process parameters using Taguchi based Grey Relational Analysis, SCI proceedia Material science 6, 1683-1695.

K.Shavinimoghaddam, H.Khayyam, M. Karbalacei Akbari, M. A.H. Praksereht, F.Abdi, M. A.Abbasi, M.Naebe (2016), Effect of $\mathrm{B}_{4} \mathrm{C}, \mathrm{TiB}_{2}$ and $\mathrm{ZrSio}_{4}$ ceramic particles on mechanical properties of aluminium matrix composites: Experimental Investigation and Predictive modelling, science Direct 42 ,6206-6220.

R.M. Leal, I. Galvao , A.Loureiro, D.M.Rodigues, Effect of friction stir processing parameters on the mechanical and electrical properties of copper Mater Int J Adv Manuf Technol DOI 10, 1007/s00170-015-7141-Z. 